\title{
Double trouble: Exploring the association between waterpipe tobacco smoking and the nonmedical use of psychoactive prescription drugs among adolescents
}

\author{
Leona Zahlan ${ }^{\mathrm{a}}$, Lilian Ghandour ${ }^{\mathrm{b}, *}$, Nasser Yassin ${ }^{\mathrm{c}}$, Rima Afifi ${ }^{\mathrm{d}}$, Silvia S. Martins ${ }^{\mathrm{a}}$ \\ a Department of Epidemiology, Columbia University Mailman School of Public Health, 722 West 168th Street, New York, NY, USA \\ ${ }^{\mathrm{b}}$ Department of Epidemiology and Population Health, Faculty of Health Sciences, American University of Beirut, Bliss street, Riad el Solh, \\ 11072020 Beirut, Lebanon \\ ${ }^{c}$ Department of Health Management and Policy, Faculty of Health Sciences, American University of Beirut, PO Box 11-0236, Riad El Solh, \\ Beirut 1107 2020, Lebanon \\ ${ }^{\mathrm{d}}$ Department of Health Promotion and Community Health, Faculty of Health Sciences, American University of Beirut, PO Box 11-0236 Riad El Solh, \\ Beirut 1107 2020, Lebanon
}

\section{A R T I C L E I N F O}

\section{Article history:}

Received 20 May 2014

Received in revised form 19 October 2014

Accepted 20 October 2014

Available online 28 October 2014

\section{Keywords:}

Adolescent

Waterpipe

Nonmedical use

Smoking

Prescription drugs

Lebanon

\begin{abstract}
A B S T R A C T
Background: In youth, both waterpipe tobacco smoking (WTS) and nonmedical use of prescription drugs (NMUPD) are globally growing concerns. This study assesses for the first time the lifetime and past-year associations between WTS and four classes of psychoactive prescription drugs.

Methods: Cross-sectional data (2011) on 986 high school students attending public and private high schools in Beirut (Lebanon) was analyzed. Schools were selected using proportionate random cluster sampling from a comprehensive list of schools provided by the Ministry of Education.

Results: Almost half (46\%) had tried WTS compared to $25 \%$ who had ever tried cigarettes. Lifetime prevalence estimates of NMUPD were: pain relievers (8.2\%), sedatives/tranquilizers (5.6\%), stimulants (3.5\%), antidepressants (2.5\%), and sleeping pills (2.3\%). WTS was associated with increased odds of sedatives/tranquilizer use ( $\mathrm{OR}=3.22,95 \% \mathrm{CI}: 1.25,8.25)$, pain reliever use $(\mathrm{OR}=4.31,95 \% \mathrm{CI}: 2.02,9.17)$, and sleeping medication use ( $\mathrm{OR}=8.31,95 \% \mathrm{CI}: 2.37,29.20)$, controlling for sex, age, school type, and other substance use. For cigarettes, the associations were consistently either weaker or non-existent, except with stimulant use (OR=5.29, 95\% CI: $1.55,18.05)$.

Conclusions: While public health professionals have watched with caution the global prevalence of youth cigarette use-worldwide, an insidious alternative form of tobacco use has grown. Further research is needed to understand the unique risk factors and motives associated with WTS and how these relate to NMUPD in order to inform the development of effective intervention programs and policies that support youth positive health decisions.
\end{abstract}

(c) 2014 Elsevier Ireland Ltd. All rights reserved.

\section{Introduction}

Waterpipe tobacco smoking (WTS)-also known as nargileh, hookah, shisha, and hubble-bubble smoking is an emerging global epidemic in the past two decades (Maziak, 2013, 2011; Nakkash et al., 2011). The Global Youth Tobacco Survey (GYTS), a school-based survey assessing changes in tobacco use over time

\footnotetext{
* Corresponding author. Tel.: +961 1 350000x4643; fax: +961 1744470 .

E-mail addresses: leonazahlan@gmail.com (L. Zahlan),

lg01@aub.edu.lb, lilian.ghandour@gmail.com (L. Ghandour), ny05@aub.edu.lb (N. Yassin),ra15@aub.edu.lb (R. Afifi),ssm2183@columbia.edu (S.S. Martins).
}

among 13-15 years old in 100 global sites, showed an unchanged prevalence of cigarette smoking in 61 sites, a decreased prevalence in 27 sites, concurrent with a rise in other tobacco use (particularly due to WTS) in 34 sites (Maziak, 2011; Warren et al., 2009). In the U.S., WTS is becoming more prevalent (Cobb et al., 2010) and is the second most smoked tobacco product among university students after cigarettes (Primack et al., 2013). Surveys of high school students in the U.S. indicated a lifetime prevalence of around $11 \%$, and one prospective study among first-year female college students found a $61 \%$ increase in lifetime prevalence of WTS after their first year of college (Barnett et al., 2009; Fielder et al., 2013).

WTS is misperceived as less harmful and addictive than cigarette smoking (Smith-Simone et al., 2008), when emerging research 
clearly indicates that WTS is comparable or worse to cigarette smoking. A smoke machine, created to emulate the actual waterpipe puff parameters, indicated that the smoke from the waterpipe contains many of the same toxicants found in cigarette smoke, including large amounts of nicotine, $\mathrm{CO}$, and tar (nicotine-free dry particulate matter; NFDPM), hydrocarbons, carcinogens, and heavy metals (Cobb et al., 2010; Shihadeh, 2003). In a recent systematic review, WTS was linked to lung cancer, respiratory illness, low birth weight, and periodontal disease (Akl et al., 2010), in addition to severe coronary artery disease (Sibai et al., 2014).

In the eastern Mediterranean region, WTS is widespread among youth (Maziak, 2013, 2011; Nakkash et al., 2011). In Lebanon, for example, the prevalence of WTS exceeded that of cigarette smoking in 2003 (29.6\% vs. $11.4 \%$ ) among a sample of 2443 private and public school students (El-Roueiheb et al., 2008). Similarly, in Damascus (Syria), a higher prevalence of WTS (23.5\% vs. $10.9 \%$ cigarette smoking) was noted in 2006-2007 among 570 medical students (Almerie et al., 2008). In Irbid (Jordan), a longitudinal study among college students, conducted between 2008 and 2011, showed a higher prevalence of WTS than cigarette smoking at every time point in the study (McKelvey et al., 2013). Recent research also suggests that waterpipe smoking at an earlier age may increase the likelihood of cigarette smoking (Jensen et al., 2010; McKelvey et al., 2013).

Another growing global public health concern, described as the fastest growing drug problem in the U.S. reaching epidemic levels, is the nonmedical use of prescription drugs (NMUPD; CDC, 2012). Reports from the United Nations Office on Drugs and Crime (UNODC), based mainly on data from the U.S. and Europe, indicate that young people are substituting the use of illicit drugs with prescription drug use, a shift that may be explained by another misperception that prescription drugs are safer than illicit drugs (UNODC, 2011). Some of the most common prescription drugs that are abused are: opioids, such as hydrocodone, oxycodone, and fentanyl; central nervous system (CNS) stimulants such as dextroamphetamine and methylphenidate; and CNS depressants, such as pentobarbital sodium and benzodiazepines. Young people obtain these non-prescribed psychoactive prescription medications from either friends or family, pharmacies, or by visiting several doctors to obtain many prescriptions (UNODC, 2011). Rise of NMUPD among adolescents is particularly problematic and worrisome because exposure to these medications could lead to addiction or overdose, experimentation with other drug use and risky behaviors such as unsafe sexual practices, not to mention interference with adolescent brain development (UNODC, 2011). Despite concern by many international bodies such as the UNODC and CDC, only one study in the past decade has investigated the issue of NMUPD among youth in the Eastern Mediterranean region, and found similar concerning patterns of use and motivations as in the U.S. (Ghandour et al., 2012).

In the U.S., NMPUD has been associated with the use of other substances including alcohol and tobacco, but namely cigarette smoking (Bali et al., 2013; Fiellin et al., 2013; Matzger and Weisner, 2007), as well as illegal drugs, including marijuana (Matzger and Weisner, 2007). For instance, Bali et al. (2013) found that people who used alcohol in the past year had more than double the odds of NMUPD compared to non-past year users $(\mathrm{OR}=2.37$, $95 \% \mathrm{CI}=1.91-2.93$ ). Similarly, a study conducted among university students from Lebanon showed that nonmedical opioid users were more likely to use marijuana, ecstasy, cocaine/crack, and alcohol problematically compared to medical users of opioids (Ghandour et al., 2013). Recently Bali et al. (2013) found that cigarette use more than doubled the odds of NMUPD. Earlier, McCabe et al. (2005) had reported that nonmedical benzodiazepine anxiolytic users were 4 times as likely as non-users to report past month cigarette use. Tetrault et al. (2008) had similarly shown that cigarette smokers aged 12 or older were twice as likely as non-smokers to use prescription opioids nonmedically.

Despite the recent rising global use of WTS, no study has yet investigated the association between WTS and NMUPD. This present study aims to examine the lifetime and past-year associations between WTS, cigarette smoking and nonmedical use of five different classes of prescription drugs.

\section{Material and methods}

\subsection{Study design and participants}

A cross-sectional survey was conducted on a representative sample of high school students attending private and public vocational and formal schools in Beirut (capital city of Lebanon) and its immediate northern and southern suburbs. In Lebanon, 70\% of youth aged 15-19 years are enrolled in an educational institution with no differences by gender (UNODC, 2011). The schools were selected using proportionate random sampling given a comprehensive list of schools provided by the Ministry of Education and Higher Education (MEHE). A total of 24 schools participated (school response rate: 68\%); student response rate in the participating schools was $57.4 \%(n=986)$.

Data collection took place between October, 2010 and March, 2011, following authorization from the MEHE, and ethical approval from the Institutional Review Board (IRB) at the American University of Beirut. Parental consent was obtained and assent forms were distributed to all students describing the objectives of the study, stressing anonymity at the level of the student (no identifiers were collected), and confidentiality at the level of the school (data analyzed aggregately across all schools). The voluntary nature of the participation was also stressed, and students were given the right to refuse participation at any point and to refuse responding to any question. Students who agreed to participate completed the paper and pencil questionnaire in their usual classroom under the supervision of a research team member, and in the absence of any teachers.

\subsection{Waterpipe and cigarette smoking}

Waterpipe smoking was assessed using one question asking the students to report whether they considered themselves to be a nonwaterpipe smoker, a former waterpipe smoker (even if once), or a current waterpipe smoker. Former and current WTS were combined to represent 'lifetime WTS smokers'. Cigarette smoking was assessed similarly.

\subsection{Nonmedical use of prescription drugs (NMUPD)}

Lifetime and past 12-month nonmedical use of five main psychoactive prescription drug categories were assessed including sedatives/tranquilizers (e.g., Xanax, Rivotril/Rivo, Lexotanil/Lexo, Valium, Ativan), pain relievers (e.g., Vicodin, Tylenol with codeine, morphine, cough syrups, Dulsana/simo, Tramal, Darvocet), stimulants (e.g., Ritalin, "stay-awake pills"), sleeping pills, (e.g., Ambien) and antidepressant medication (e.g., Prozac, Zoloft, Effexor). Market available trade names were given as examples to increase identification and reduce information errors. Nonmedical use of these medications was defined as using prescription drugs that were prescribed for somebody else, using the medications for longer periods than prescribed for them by their own doctor, or using the medications to get high for reasons other than what the medication is intended for. 


\subsection{Potential confounders}

Relevant literature was thoroughly reviewed to identify important variables that may confound the relation between WTS and NMUPD (McCabe et al., 2005; Opaleye et al., 2013); potential confounders adjusted for in this study include age, sex, school type and use of various substances. Lifetime alcohol consumption was defined as ever having had an alcoholic drink, other than just a sip or two. Past 12-month alcohol use was derived from the following question: "When was the last time you had any alcoholic drink?" and options were combined to reflect within the last 12 months (i.e., past 12 -month user) or more than 1 year ago (i.e., nonpast 12 months user). Students were also asked about frequency of past-year drinking, and students who drank 1 or 2 days a week or more were categorized as 'regular drinkers' versus not (1or 3 days per month or less). Lifetime illegal drug use was also assessed: ever trying marijuana and/or hashish, ecstasy, heroin, cocaine, LSD, amphetamines/stimulants, and inhalants; using any of these substances at least once within the past 12 months was also measured (i.e., past-year illegal drug use).

\subsection{Statistical analyses}

Using Stata (version 12.0), Pearson's chi-square test was used to investigate bivariate associations, and binary logistic regressions were run to examine the strength and precision of the associations controlling for potential confounders. Three regression models were run: model 1 is the unadjusted model; model 2 adjusted for sex, age, and type of school; and model 3 further adjusted for lifetime use of other substances. For comparative purposes, the commonly investigated association between cigarette use and NMUPD was also examined. Complex survey data analysis was conducted (using the 'svy' command); sampling weights were included to maintain the proportionate representative sample initially selected and to account for non-response rate.

\section{Results}

\subsection{Sample descriptives}

The sample (age range: $14-32$ years; mean age: $16.8 \pm 0.06$ years old) includes more females (62.3\%), and students enrolled in private schools (59.2\% in formal and $22.1 \%$ in private vocational). Most self-rated themselves as 'well above average' or 'somewhat above average' (31.1\% and $47.9 \%$, respectively) academically. The majority $(68.7 \%)$ reported that their parents would be very upset if they thought their kids had used prescription drugs for nonmedical reasons. The survey did not inquire about parental attitude toward tobacco smoking. With regards to their weekly pocket money, the distribution was as follows: $7 \%$ received $<10000$ Lebanese pounds (LBP), 11,000-20,000 LBP (26\%), 21,000-30,000 LBP (22\%), $31,000-40,000$ LBP (9\%), 41,000-50,000 LBP (11\%), and >50,000 LBP (18\%). One United States Dollar (USD) is equivalent to 1500 LBP.

\subsection{Prevalence of substance use}

Table 1 presents the weighted lifetime and past-year estimates of all substance use measures. Almost half of the high school students (46.1\%) had smoked waterpipe in their lifetime versus $25.1 \%$ lifetime cigarettes smokers; approximately 1 in 4 were current waterpipe smokers compared to 1 in 10 cigarettes smokers (Table 1). About half of the sample was lifetime and past year alcohol drinkers; 1 in 5 students were current regular alcohol drinkers, or drank 1 or 2 days per week or more in the preceding year; an additional $25.3 \%$ were occasional drinkers, or drank 1 or 3 days per month or less in the past 12 -months
Table 1

Distribution of lifetime and current substance use measures among 986 high school students attending private and public formal and vocational schools in Greater Beirut, Lebanon.

\begin{tabular}{llc}
\hline Substance use measures & Lifetime & Current \\
\hline & $n(\%)$ & $n(\%)$ \\
\hline Waterpipe smoking & & \\
$\quad$ No waterpipe use & $471(51.0)$ & $662(71.3)$ \\
Any waterpipe use & $481(46.1)$ & $290(25.8)$ \\
Cigarette smoking & & \\
$\quad$ No cigarette use & $724(72.0)$ & $858(87.2)$ \\
Any cigarette use & $226(25.1)$ & $92(9.9)$ \\
Illicit drug use & & \\
$\quad$ No illicit drug use & $858(88.2)$ & $872(89.7)$ \\
Any illicit drug use & $77(7.3)$ & $63(5.7)$ \\
Lifetime alcohol use & $506(48.1)$ & - \\
$\quad$ No Alcohol Use & $455(49.6)$ & \\
alcohol use & & $529(50.2)$ \\
Alcohol drinking status & - & $225(25.3)$ \\
Non/former drinker & - & $185(19.9)$ \\
Current occasional drinker & - & $46(3.5)$ \\
Current regular drinker & & $69(6.2)$ \\
NMUPD & $69(5.6)$ & $21(2.1)$ \\
Any tranquilizer/sedative use & $97(8.2)$ & $15(1.0)$ \\
Any pain reliever use & $33(3.5)$ & $18(1.3)$ \\
Any stimulant use & $27(2.3)$ & \\
Sleeping medications & $30(2.5)$ & \\
Any antidepressant use & & \\
\hline
\end{tabular}

Note. Current illicit drug use and NMUPD (nonmedical use of prescription drugs) refer to any past 12 month use. Lifetime waterpipe and cigarette smokers include current and former smokers. Current regular drinkers include students who drank 1 or 2 days a week or more; occasional drinkers includes students who drank 1 or 3 days per month or less.

-: Not assessed; \%: denotes valid percent.

(Table 1). With regards to NMUPD, the highest lifetime and current (past 12-months) prevalence (respectively) were for pain relievers $(8.24 \%, 6.18 \%$, respectively), followed by sedatives/tranquilizers (5.6\%, 3.5\%), stimulants (3.5\%, 2.1\%), antidepressants (2.5\%, $1.3 \%)$, and lastly sleeping medications (2.3\%, $1.0 \%$; Table 1$)$.

\subsection{Lifetime measures of WTS, cigarette smoking and NMUPD}

As shown in Table 2.1, neither cigarette smoking nor WTS were associated with the lifetime use of antidepressant medications. Lifetime waterpipe smoking was statistically significantly associated with greater odds of using sedative/tranquilizers (3-fold increase), pain relievers (4-fold increase), and sleeping medications (5-fold increase), even after controlling for all potential confounders (Table 2.1, model 3). Lifetime cigarette smoking was statistically significantly associated with the use of sedatives/tranquilizers and sleeping medications, adjusted for sex, age and education type (Table 2.1, model 2) but not upon further controlling for other substance use measures (Table 2.1, model 3). Interestingly, lifetime cigarette smokers (but not WTS) were approximately 5 times as likely to report stimulant use compared to never cigarette smokers, even after adjustment (Table 2.1, model $3)$.

\subsection{Current measures of WTS, cigarette smoking and NMUPD}

Neither current cigarette nor current WTS were related to past year antidepressant use. Current WTS were more than twice as likely to also report past-year sedative/tranquilizer use and pain reliever use, controlling for students' age, sex and education type (Table 2.2, model 2); no other associations were observed between past-year WTS and past-year use of other prescription drugs (Table 2.2). 
Table 2.1

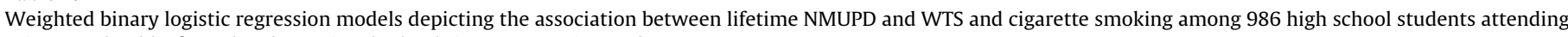
private and public formal and vocational schools in Greater Beirut, Lebanon.

\begin{tabular}{|c|c|c|c|c|}
\hline \multirow[t]{2}{*}{ Lifetime NMUPD } & \multicolumn{2}{|l|}{ Lifetime WTS ${ }^{a}$} & \multicolumn{2}{|c|}{ Lifetime cigarette smoker ${ }^{\mathrm{b}}$} \\
\hline & OR $(95 \% \mathrm{CI})$ & $p$-Value & OR $(95 \% \mathrm{CI})$ & $p$-Value \\
\hline \multicolumn{5}{|c|}{ Sedatives/tranquilizer medications $(n=69)$} \\
\hline Model 1 & $6.98(3.00,16.27)$ & $<0.001$ & $4.90(2.56,9.39)$ & $<0.001$ \\
\hline Model 2 & $6.28(2.67,14.76)$ & $<0.001$ & $5.02(2.64,9.56)$ & $<0.001$ \\
\hline Model 3 & $2.98(1.10,8.04)$ & 0.031 & $2.29(1.00,5.23)$ & 0.050 \\
\hline \multicolumn{5}{|c|}{ Pain Reliever medications $(n=69)$} \\
\hline Model 1 & $4.18(2.23,7.84)$ & $<0.001$ & $1.50(0.85,2.67)$ & 0.161 \\
\hline Model 2 & $4.27(2.19,8.32)$ & $<0.001$ & $1.60(0.85,3.01)$ & 0.147 \\
\hline Model 3 & $4.35(2.05,9.25)$ & $<0.001$ & $0.75(0.36,1.54)$ & 0.429 \\
\hline \multicolumn{5}{|c|}{ Stimulant medications $(n=21)$} \\
\hline Model 1 & $1.91(0.79,4.63)$ & 0.152 & $4.21(1.80,9.89)$ & 0.001 \\
\hline Model 2 & $1.87(0.76,4.62)$ & 0.173 & $4.19(1.76,9.96)$ & 0.001 \\
\hline Model 3 & $0.86(0.24,2.99)$ & 0.806 & $5.09(1.29,20.04)$ & 0.020 \\
\hline \multicolumn{5}{|c|}{ Sleeping Medications $(n=27)$} \\
\hline Model 1 & $7.04(2.08,23.80)$ & 0.002 & $2.89(1.05,7.96)$ & 0.040 \\
\hline Model 2 & $6.54(1.68,25.40)$ & 0.007 & $2.83(1.00,7.98)$ & 0.049 \\
\hline Model 3 & $4.74(1.16,19.27)$ & 0.030 & $1.66(0.57,4.81)$ & 0.351 \\
\hline \multicolumn{5}{|c|}{ Antidepressant medications $(n=30)$} \\
\hline Model 1 & $2.53(0.93,6.87)$ & 0.069 & $1.54(0.56,4.20)$ & 0.427 \\
\hline Model 2 & $2.39(0.80,7.10)$ & 0.116 & $1.54(0.56,4.27)$ & 0.405 \\
\hline Model 3 & $2.02(0.62,6.61)$ & 0.243 & $1.13(0.39,3.24)$ & 0.820 \\
\hline
\end{tabular}

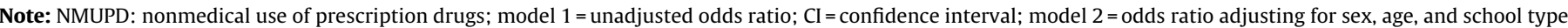

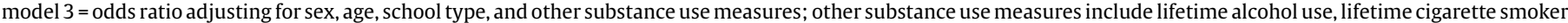

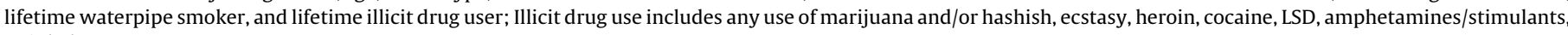
or inhalants.

a Reference category = non WTS (waterpipe tobacco smoker).

b Reference category = non cigarette smoker; Bolded items indicate statistically significant results (alpha =0.05).

Unlike lifetime cigarette smokers, current cigarette smokers were at higher odds of also reporting past-year sedative/ tranquilizer use (a 6-fold increase adjusted for all confounders), past-year sleeping medication use (a 12-fold increase, adjusted for all confounding measures), in addition to past-year stimulant use (a 4-fold increase controlling for age, sex and education type; Table 2.2).

\section{Discussion}

This study makes several contributions to the literature with regards to youth WTS and NMUPD, and builds on prior work that investigates substance use correlates of NMUPD. Specifically, its findings: (1) indicate a significantly higher prevalence of lifetime and current WTS among high school students in

Table 2.2

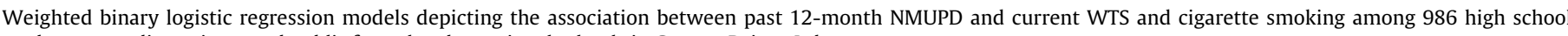
students attending private and public formal and vocational schools in Greater Beirut, Lebanon.

\begin{tabular}{|c|c|c|c|c|}
\hline \multirow[t]{2}{*}{ Past year NMUPD } & \multicolumn{2}{|l|}{ Current WTS } & \multicolumn{2}{|c|}{ Current cigarette smoker ${ }^{\mathrm{b}}$} \\
\hline & OR $(95 \% \mathrm{CI})$ & $p$-Value & OR $(95 \% \mathrm{CI})$ & $p$-Value \\
\hline \multicolumn{5}{|c|}{ Sedatives/Tranquilizer medications $(n=69)$} \\
\hline Model 1 & $3.50(1.62,7.56)$ & 0.001 & $9.27(4.11,20.90)$ & $<0.001$ \\
\hline Model 2 & $2.97(1.30,6.79)$ & 0.010 & $12.11(5.77,25.45)$ & $<0.001$ \\
\hline Model 3 & $1.31(0.43,3.98)$ & 0.633 & $6.53(2.04,20.88)$ & 0.002 \\
\hline \multicolumn{5}{|c|}{ Pain reliever medications $(n=69)$} \\
\hline Model 1 & $2.48(1.32,4.65)$ & 0.005 & $1.36(0.59,3.13)$ & 0.469 \\
\hline Model 2 & $2.67(1.33,5.35)$ & 0.006 & $1.65(0.61,4.45)$ & 0.326 \\
\hline Model 3 & $2.13(0.92,4.92)$ & 0.076 & $0.57(0.20,1.64)$ & 0.298 \\
\hline \multicolumn{5}{|c|}{ Stimulant medications $(n=21)$} \\
\hline Model 1 & $1.04(0.33,3.29)$ & 0.944 & $3.27(1.00,10.66)$ & 0.050 \\
\hline Model 2 & $1.00(0.31,3.22)$ & 0.995 & $4.14(1.34,12.80)$ & 0.014 \\
\hline Model 3 & $0.56(0.10,3.20)$ & 0.514 & $3.46(0.57,20.84)$ & 0.176 \\
\hline \multicolumn{5}{|c|}{ Sleeping medications $(n=27)$} \\
\hline Model 1 & $0.89(0.28,2.85)$ & 0.850 & $8.04(2.01,32.22)$ & 0.003 \\
\hline Model 2 & $0.64(0.19,2.11)$ & 0.462 & $9.34(2.25,38.86)$ & 0.002 \\
\hline Model 3 & $0.27(0.06,1.18)$ & 0.082 & $11.52(1.27,104.81)$ & 0.030 \\
\hline \multicolumn{5}{|c|}{ Antidepressant medications $(n=30)$} \\
\hline Model 1 & $1.67(0.46,6.00)$ & 0.434 & $2.61(0.61,11.13)$ & 0.194 \\
\hline Model 2 & $1.27(0.25,6.56)$ & 0.773 & $1.98(0.48,8.19)$ & 0.348 \\
\hline Model 3 & $0.84(0.10,7.04)$ & 0.873 & $1.08(0.29,4.00)$ & 0.904 \\
\hline
\end{tabular}

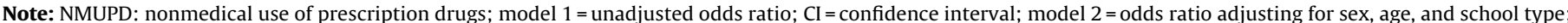

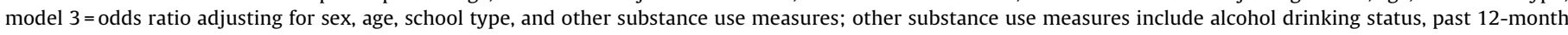

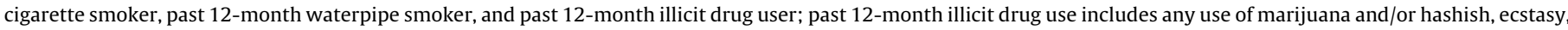
heroin, cocaine, LSD, amphetamines/stimulants, or inhalants.

a Reference category = non-current WTS (waterpipe tobacco smoker).

b Reference category = non-current cigarette smoker; Bolded items indicate statistically significant results (alpha $=0.05)$. 
Lebanon, than cigarette smokers, corroborating other study findings (Almerie et al., 2008; El-Roueiheb et al., 2008; WHO, 2012; Maziak, 2013; McKelvey et al., 2013); (2) highlight strong and statistically significant associations between WTS and NMUPD, namely sedatives/tranquilizers, pain relievers, and sleeping pills, even after adjusting for multiple potential confounders; and, (3) suggest no association between WTS and stimulant use, contrary to cigarette smoking which is associated with a four-fold increase in stimulant use.

Lifetime WTS among adolescents was significantly and robustly (after adjusting for confounders) associated with the lifetime nonmedical use of sedatives/tranquilizers, pain relievers, and sleeping medications. One possible explanation may be the perception of the similar effects of WTS and the associated prescription drugs. Meaning, while the nicotine in waterpipe is a mild stimulant, waterpipe is most smoked as part of a 'social event or gathering' and is more associated with happiness and relaxation, as reported in focus groups and key informant interviews from the eastern Mediterranean region (Afifi et al., 2013). Sedatives/tranquilizers (sedative-hypnotics), pain relievers (opioids), and sleeping medications act as CNS depressants by increasing the neurotransmitter gamma-amino butyric acid (GABA) and inhibiting brain activity to produce a calming or drowsy effect to induce sleep or reduce anxiety (Volkow, 2011). It is worth noting here that the only previous study from Lebanon assessing NMUPD showed that the majority of the nonmedical users of prescription drugs used the medication for its 'intended therapeutic purpose' even though the drug was not prescribed for them (Ghandour et al., 2012). So, from a medical perspective, and this hypothesis has yet to be investigated, it is possible that a portion of the students (yet to be determined) may be using WTS as "self-medication" for untreated anxiety/depression symptoms, which would require they combine its use with other prescription drugs with somewhat similar pharmacological properties (and not with stimulants) (Khantzian, 1997). This may not be the case with antidepressants because they do not have immediate psychoactive effects as compared to sedatives such as Xanax (i.e., antidepressant effects are usually seen at least 7-15 days after first intake if taken on a regular basis). Moreover, it is more culturally acceptable in Lebanon for youth to self-medicate or for parents to "medicate" their children with sedatives (than antidepressants) as it is not uncommon for parents to have such prescription drugs available at home for their own non-prescribed use. In fact, in a recent university survey from Lebanon, parents were the leading reported source for obtaining pain, anxiety, and sleeping medications among nonmedical users (Ghandour et al., 2012). Sedatives are also generally perceived to be "safer" compared to antidepressants due to parents' misconception that sedatives, such as Xanax, could be given on an "as needed basis" rather than a lifelong and continuous treatment of antidepressants.

Unlike WTS, cigarette smoking was associated with stimulant medications, and one of many possible hypotheses is that these adolescents may have an underlying and untreated attentiondeficit/hyperactivity disorder (ADHD) since cigarette smoking is highly prevalent in this population and stimulants are typically used to treat those with ADHD. Research suggests that those with ADHD may self-medicate using cigarettes since nicotine improves attention and social functioning (Liebrenz et al., 2014). This population may be smoking cigarettes rather than waterpipe due to the quicker process of obtaining and smoking cigarettes(versus the more social nature of WTS) and the immediate psychoactive effects of inhaling a cigarette to treat ADHD symptoms (Liebrenz et al., 2014; Schoenfelder et al., 2014).

Another less specific explanation for these strong associations between WTS and NMUPD may be the acknowledged concomitant use of a variety of substances among adolescents (Boyd et al., 2009; Teesson et al., 2012). Various possible hypotheses have been posed for this co-occurrence, including the stepping stone hypothesis (Teesson et al., 2012), which suggests that individuals who begin using licit drugs increase their risk to illicit drug use. Alternatively, illicit drug use may increase the risk of licit drug use, or a common factor (e.g., genetic predisposition, family circumstances) may be the underlying cause for the co-occurrence. Testing for causal associations is beyond the scope of our cross-sectional study, but nonetheless we did attempt to test for comorbidity due to common causes by controlling for other substance use measures as potential confounders.

\subsection{Strengths and limitations}

Despite its important findings, the present study is not void of limitations including our inability to establish temporality, as is the case in all cross-sectional studies. However, cigarette use has been proven to be a gateway to the use of other substances (Bali et al., 2013; Fiellin et al., 2013) most likely due to the tobacco effect rather than the particular form through which tobacco is used-thus supporting our suggestion of direction of association. Our school-level response rate is a reported average (68\%) whereby it was $100 \%$ for all public schools and $33.33 \%$ for formal private, and $38 \%$ for formal vocational; worth noting here is that the $100 \%$ participation from the public sector is due to the fact that an approval from MEHE obliges all public schools to partake in the survey (maintaining the voluntary nature at the participant level); private schools in Lebanon, however, do not fall under the jurisdiction of MEHE, and retain their right to refuse participation. This challenge to recruitment of private schools is not intrinsic to our study; authors of another school-based study from Beirut reported $100 \%$ participation for randomly selected public schools and only 43\% (10 of 23) for the private schools (El-Roueiheb et al., 2008; Tamim et al., 2007). Knowing that participation rates for epidemiological studies have declined during the past 30 years (Galea and Tracy, 2007), we found that our student response rate (57\%) was lower than that reported in selected school-based surveys in the U.S. (89\%; Havens, 2011), Brazil (79\%; Opaleye et al., 2013), and Jordan (95\%; Alzyoud et al., 2013), but also quite comparable or higher to others [Boyd et al., 2009 (64\%); Cranford et al., 2013 (62\%); Jayawardene \& YoussefAgha, 2014 (34\%)]. Quite important also however, is the comparability of our sample characteristics, with regards to the distribution of students by age and sex, to that of student characteristics at the population-level (as reported by MEHE). While we cannot claim that our findings are generalizable to other adolescents not enrolled in school, or enrolled outside the Greater Beirut area, the fact that they are highly consistent with observations from the U.S. and Europe, speaks to their external validity. Recall bias, while also possible, is likely to be minimal in this young adolescent population. The self-report nature of the survey is likely to have minimized social desirability bias. Still, the survey did not assess the quantity or frequency of use of prescription drugs, or waterpipe or cigarettes. While the latter is unquestionably important, any lifetime use is important to analyze and understand given the young age and vulnerability of this adolescent sample.

Notwithstanding these limitations are some offsetting strengths namely it being the first study to investigate WTS and NMUPD in a relatively large $(n=986)$, representative sample of high school students. Its findings have several important implications for future research and practice, and are an important stepping-stone to future surveys. It appears (given the prevalence estimates) that many users may perceive prescription drugs to be safer than illicit drugs and WTS to be a safer alternative to cigarette smoking. For the first time, this study shows that the associations of WTS and NMUPD are similar and even stronger than those observed for 
cigarette smoking and NMUPD (at least in this sample, and except in the case of stimulant use), which debunks the myth that waterpipe smokers are mere social smokers with no further risks.

\subsection{Conclusion}

As public health practitioners concerned about youth substance use have watched with caution the increasing prevalence of NMPUD and the declining use of cigarettes worldwide, an insidious alternative form of tobacco use has grown. Future studies, both quantitative and qualitative in nature, should therefore try and understand the unique risk factors and motives associated with WTS and how these relate to the nonmedical use of specific prescription drugs. Further longitudinal studies, similar to those conducted on cigarette use (Log et al., 2011), can also build on our study, and researchers could emulate their work on cigarette and NMUPD use with WTS given its unique characteristics. Meanwhile, and since WTS and NMPUD are becoming global threats with serious related health risks, it is important to continue raising awareness on the harms associated with the use of all substances-focusing on new and emerging threats such as WTS and NMUPD- among various stakeholders including adolescents, parents, teachers, physicians, as well as policy implementers; and to implement evidence-informed public health programs and policies that support positive health decisions of adolescents.

\section{Author disclosures}

\section{Role of funding source}

Dr. Martins is currently supported by NICHD-NIH 1R01HD060072 and by a Columbia University President's Global Innovation Fund (UR008509). The present study was funded by the Swiss Academy for Development-who had no further role in the study.

\section{Contributors}

Leona Zahlanis a graduate student who completed this work as part of her master's thesis requirement. Lilian Ghandour, the corresponding author and co-principal investigator on the grant, was involved in all stages of the research study; was responsible for supervising the analysis and work of Leona Zahlan during her thesis; and contributed extensively to the writing of the manuscript. Nasser Yassin (PI on the grant) and Rima Afifi (co-PI) were involved in the conceptualization and implementation of the study. Silvia Martins co-supervised the work of Leona Zahlan as her main advisor. All authors reviewed and edited the final draft of the manuscript.

\section{Conflict of interest statement}

Dr. Martins is currently a consultant for PurduePharma to conduct secondary data analysis of U.S. public use adult data on nonmedical prescription opioid use and alcohol use. All other authors declare no conflict of interest.

\section{Acknowledgments}

The authors would like to thank Ms. Dima Bteddini for being involved in the planning and implementation of instrument development, training of interviewers, field coordination, and data entry and Ms. Donna El-Sayed for assistance with data collection, data entry, and data cleaning. We would like to also thank
Dr. Fadi Maalouf for his insightful interpretation of the findings from a contextual clinical perspective, and Ms. Noura El Salibi for her help in editing the final versions of the manuscript.

\section{References}

Afifi, R., Khalil, J., Fouad, F., Hammal, F., Jarallah, Y., Abu Farhat, H., Ayad, M., Nakkash, R., 2013. Social norms and attitudes linked to waterpipe use in the eastern Mediterranean region. Soc. Sci. Med. 98, 125-134, http://dx.doi.org/10.1016/j.socscimed.2013.09.007.

Akl, E.A., Gaddam, S., Gunukula, S.K., Honeine, R., Jaoude, P.A., Irani, J., 2010. The effects of waterpipe tobacco smoking on health outcomes: a systematic review. Int. J. Epidemiol. 39, 834-857, http://dx.doi.org/10.1093/ije/dyq002.

Almerie, M.Q., Matar, H.E., Salam, M., Morad, A., Abdulaal, M., Koudsi, A., Maziak, W., 2008. Cigarettes and waterpipe smoking among medical students in Syria: a cross-sectional study. Int. J. Tuberc. Lung Dis. 12, 1085.

Alzyoud, S., Weglicki, L., Kheirallah, K., Haddad, L., Alhawamdeh, K., 2013. Waterpipe smoking among middle and high school Jordanian students: patterns and predictors. Int. J. Environ. Res. Public Health 10, 7068-7082 http://dx.doi.org/10.3390/ijerph10127068.

Bali, V., Raisch, D.W., Moffett, M.L., Khan, N., 2013. Determinants of nonmedical use, abuse or dependence on prescription drugs, and use of substance abuse treatment. Res. Social Adm. Pharm. 9, 276-287, http://dx.doi.org/10.1016/ j.sapharm.2012.04.008.

Barnett, T., Curbow, B., Weitz, J., Johnson, T., Smith-Simone, S., 2009. Water pipe tobacco smoking among middle and high school students. Am. J. Public Health 99, 2014-2019.

Boyd, C.J., Young, A., Grey, M., McCabe, S.E., 2009. Adolescents' nonmedical use of prescription medications and other problem behaviors. J. Adolesc. Health 45 , 543-550, http://dx.doi.org/10.1016/j.jadohealth.2009.03.023.

Centers for Disease Control Prevention (CDC), 2012. CDC grand rounds: prescription drug overdoses-a US epidemic. MMWR.10-13.

Cobb, C., Ward, K.D., Maziak, W., Shihadeh, A.L., Eissenberg, T., 2010. Waterpipe tobacco smoking: an emerging health crisis in the United States. Am. J. Health Behav. 34, 275.

Cranford, J.A., McCabe, S.E., Boyd, C.J., 2013. Adolescents' nonmedical use and excessive medical use of prescription medications and the identification of substance use subgroups. Addictive Behav. 38 (11), 2768-2771, http://dx.doi.org/10.1016/j.addbeh.2013.06.015.

Khantzian, E., 1997. The self-medication hypothesis of substance use disorders a reconsideration and recent applications. Harv. Rev. Psychiatry 4, 231-244, http://dx.doi.org/10.3109/10673229709030550.

El-Roueiheb, Z., Tamim, H., Kanj, M., Jabbour, S., Alayan, I., Musharrafieh, U., 2008. Cigarette and waterpipe smoking among Lebanese adolescents, a cross-sectional study, 2003-2004. Nicotine Tob. Res. 10, 309-314, http://dx.doi.org/10.1080/14622200701825775.

Fielder, R.L., Carey, K.B., Carey, M.P., 2013. Hookah, cigarette, and marijuana use a prospective study of smoking behaviors among first-year college women. Addict. Behav. 38, 2729-2735, http://dx.doi.org/10.1016/j.addbeh.2013.07.006.

Fiellin, L.E., Tetrault, J.M., Becker, W.C., Fiellin, D.A., Hoff, R.A., 2013. Previous use of alcohol, cigarettes, and marijuana and subsequent abuse of prescription opioids in young adults. J. Adolesc. Health 52, 158-163, http://dx.doi.org/10.1016/j.jadohealth.2012.06.010.

Galea, S., Tracy, M., 2007. Participation rates in epidemiologic studies. Ann. Epidemiol. 17, 643-653, http://dx.doi.org/10.1016/j.annepidem.2007.03.013.

Ghandour, L.A., El Sayed, D.S., Martins, S.S., 2012. Prevalence and patterns of commonly abused psychoactive prescription drugs in a sample of university students from Lebanon: an opportunity for cross-cultural comparisons. Drug Alcoho Depend. 121, 110-117, http://dx.doi.org/10.1016/j.drugalcdep.2011.08.021.

Ghandour, L.A., El Sayed, D.S., Martins, S.S., 2013. Alcohol and illegal drug use behaviors and prescription opioids use: how do nonmedical and medical users compare, and does motive to use really matter? Eur. Addict. Res. 19, 202-210 http://dx.doi.org/10.1159/000345445.

Havens, J.R., 2011. Nonmedical prescription drug use in a nationally representative sample of adolescents. Arch. Pediatr. Adolesc. Med. 165, 250 http://dx.doi.org/10.1001/archpediatrics.2010.217.

Jayawardene, W.P., YoussefAgha, A.H., 2014. Multiple and Substitute Addictions Involving Prescription Drugs Misuse Among 12th Graders: Gateway Theory Revisited With Market Basket Analysis. J. Addiction Med. 8 (2), 102-110, http://dx.doi.org/10.1097/ADM.0000000000000012.

Jensen, P.D., Cortes, R., Engholm, G., Kremers, S., Gislum, M., 2010. Waterpipe use predicts progression to regular cigarette smoking among danish youth. Subst Use Misuse 45, 1245-1261, http://dx.doi.org/10.3109/10826081003682909.

Liebrenz, M., Frei, A., Fisher, C.E., Gamma, A., Buadze, A., Eich, D., 2014. Adult attention-deficit/hyperactivity disorder and nicotine use: a qualitative study of patient perceptions. BMC Psychiatry 14, 141

Log, T., Hartz, I., Handal, M., Tverdal, A., Furu, K., Skurtveit, S., 2011. The association between smoking and subsequent repeated use of prescribed opioids among adolescents and young adults-a population-based cohort study. Pharmacoepidemiol. Drug Saf. 20, 90-98, http://dx.doi.org/10.1002/pds.2066.

Matzger, H., Weisner, C., 2007. Nonmedical use of prescription drugs among a longitudinal sample of dependent and problem drinkers. Drug Alcohol Depend. 86, 222-229, http://dx.doi.org/10.1016/j.drugalcdep.2006.06.010. 
Maziak, W., 2011. The global epidemic of waterpipe smoking. Addict. Behav. 36, 1-5, http://dx.doi.org/10.1016/j.addbeh.2010.08.030.

Maziak, W., 2013. The waterpipe: an emerging global risk for cancer. Cancer Epidemiol. 37, 1-4, http://dx.doi.org/10.1016/j.canep.2012.10.013.

McCabe, S.E., Teter, C.J., Boyd, C.J., Knight, J.R., Wechsler, H., 2005. Nonmedical use of prescription opioids among U.S. college students: prevalence and correlates from a national survey. Addict. Behav. 30, 789-805, http://dx.doi.org/10.1016/j.addbeh.2004.08.024.

McKelvey, K.L., Wilcox, M.L., Madhivanan, P., Mzayek, F., Khader, Y.S., Maziak, W. 2013. Time trends of cigarette and waterpipe smoking among a cohort of school children in Irbid, Jordan, 2008-2011. Eur. J. Public Health 23, 862-867, http://dx.doi.org/10.1093/eurpub/ckt140.

Nakkash, R.T., Khalil, J., Afifi, R.A., 2011. The rise in narghile (shisha, hookah) waterpipe tobacco smoking: a qualitative study of perceptions of smokers and non smokers. BMC Public Health 11, 315

Opaleye, E.S., Noto, A.R., Sanchez, Z.M., Amato, T.C., Locatelli, D.P., Gossop, M., Ferri, C.P., 2013. Nonprescribed use of tranquilizers or sedatives by adolescents: a Brazilian national survey. BMC Public Health 13, 499.

Primack, B.A., Shensa, A., Kim, K.H., Carroll, M.V., Hoban, M.T., Leino, E.V., Eissenberg, T., Dachille, K.H., Fine, M.J., 2013. Waterpipe smoking among U.S university students. Nicotine Tob. Res. 15, 29-35, http://dx.doi.org/10.1093/ntr/ nts076.

Schoenfelder, E.N., Faraone, S.V., Kollins, S.H., 2014. Stimulant treatment of adhd and cigarette smoking: a meta-analysis. Pediatrics 133, 1070-1080, http://dx.doi.org/10.1542/peds.2014-0179.

Shihadeh, A., 2003. Investigation of mainstream smoke aerosol of the argileh water pipe. Food Chem. Toxicol. 41, 143-152.

Sibai, A.M., Tohme, R.A., Almedawar, M.M., Itani, T., Yassine, S.I., Nohra, E.A., Isma'eel, H.A., 2014. Lifetime cumulative exposure to waterpipe smoking is associated with coronary artery disease. Atherosclerosis 234, 454-460, http://dx.doi.org/10.1016/j.atherosclerosis.2014.03.036.

Smith-Simone, S., Maziak, W., Ward, K., Eissenberg, T., 2008. Waterpipe tobacco smoking: knowledge, attitudes, beliefs, and behavior in two U.S. samples. Nicotine Tob. Res. 10, 393-398, http://dx.doi.org/10.1080/14622200701825023.

Tamim, H., Al-Sahab, B., Akkary, G., et al., 2007. Cigarette and nargileh smoking practices among school students in Beirut Lebanon. Am. J. Health Behav. 31 (1), 56-63.

Tetrault, J.M., Desai, R.A., Becker, W.C., Fiellin, D.A., Concato, J., Sullivan, L.E., 2008. Gender and non-medical use of prescription opioids: results from a national US survey*. Addiction 103, 258-268, http://dx.doi.org/10.1111/ j.1360-0443.2007.02056.x

Teesson, M., Farrugia, P., Mills, K., Hall, W., Baillie, A., 2012. Alcohol, tobacco, and prescription drugs: the relationship with illicit drugs in the treatment of substance users. Subst. Use Misuse 47, 963-971, http://dx.doi.org/10.3109/10826084.2012.663283.

UNODC, 2011. The non-medical use of prescription drugs. In: WWW Document http://www.unodc.org/docs/youthnet/Final_Prescription_Drugs_Paper.pdf (accessed 11.14.13) 2013

Volkow, N.D., 2011. Prescription Drugs: Abuse and Addiction. Natl. Inst. Drug Abuse

Warren, C.W., Lea, V., Lee, J., Jones, N.R., Asma, S., McKenna, M., 2009. Change in tobacco use among 13-15 year olds between 1999 and 2008: findings from the Global Youth Tobacco Survey. Glob. Health Promot. 16, 38-90, http://dx.doi.org/10.1177/1757975909342192.

World Health Organization Regional Office for the Eastern Mediterranean (WHO EMRO), 2012. Global Youth Tobacco Survey Country fact sheets, http://www.emro.who.int/images/stories/tfi/documents/GYTS_FS_LEB_2011. pdf?ua=1 (accessed 2.08.14) 